\title{
Editorials
}

\section{Authors are not criminals and editors should not be policemen}

\author{
POVL MUNK JORGENSEN
}

\begin{abstract}
Authors are a necessary and most appreciated basis for the publishing of any scientific journal. They should be welcomed for their creativity, originality and productivity, not stigmatized in general as cheaters and criminals because a very few were tempted beyond their control to cut the slices a bit too thin, overdo the utilization of leftover data, listed too many authors to a paper, forgot to report a harmless study to an ethical committee, or in very few cases commit severe actions of fraud.

The managerial way of thinking, meeting every author with systems of control and limitations is like poison to creative minds. Instead of appointing editors as policemen, we may preferably meet the vast majority of classical scholarly working scientists with trust, confidence and support, facilitating the process of disseminating the results from their creative minds - and of course consequently show the deliberately cheating researchers the door when they act unfaithfully to the scientific society.

Declaration of Interest: Povl Munk-Jorgensen has since January 2007 received non-conditional grants, and/or minor honoraria from H. Lundbeck A/S, AstraZeneca, Eli Lilly, Janssen-Cilag A/S and Bristol-Myers Squibb.
\end{abstract}

In 2003, the editor of Epidemiologia e Psichiatria Sociale (EPS) invited representatives from a handful of European psychiatric journals to write an editorial about editing scientific psychiatric journals.

Having been kindly invited to write a follow-up to my 2003 contribution, it was an opportunity to look at what was on my mind seven years ago concerning publishing a scientific journal.

I considered several topics for this follow-up editorial relating the Acta Psychiatrica Scandinavica to the 2003 editorial (Munk-Jørgensen, 2003). For instance, the revolution in publishing technology, the ongoing debate about the organization of publishing including, among other topics, open access, the question about publishing for the $\mathrm{CV}$ versus publishing for the science, the change of attitude in the publishing process from the scientific community to business school principles. I was very much tempted to elaborate on my experiences of corresponding with between 600 and 700 authors every year (MunkJørgensen et al., 2010), or about how journals gradually

Address for correspondence: Professor P. Munk-Jørgensen, Editorin-chief Acta Psychiatrica Scandinavica, Unit for Psychiatric Research, Aalborg Psychiatric Hospital, Aarhus University Hospital, DK-9000 Aalborg (Denmark).

Fax: +4572137235

E-mail:pmj@rn.dk develop in profile and structure (Munk-Jørgensen et al., 2009), or the increasingly infiltrating mutual mistrust in publishing - thinking of authors as potential cheaters and criminals, or persons behaving unethically to gain money and prestige.

I chose the latter, adding a few considerations about the influence of the introduction of the electronic editing process.

Editors are supposed to invest an increasing part of the editing work in controlling authors' and reviewers' legal and ethical behaviour. Editors must ensure that authors declare themselves, especially their relations to the pharma-industry; they must ensure that all authors have contributed sufficiently to the research being published and to the publication. Editors must check ethical rules concerning researchers' relationships to their probands/ patients and in relation to other researchers and authors; they must control that pharma-studies are registered in different databases, etc.

When all this has been done, the editors can start doing what they are basically supposed to do: identify the best research and take control of an evaluation of its originality and quality, and promote its publication, circulation and dissemination.

The whole field of publishing illustrated above is parallel to how health care is administered. The physicians cannot see patients, do research or teach until they have completed registration to the administrative databases,

Epidemiologia e Psichiatria Sociale, 19, 3, 2010 
until they have finished participating in endless meetings about organization, have taken precautions to ensure that the hospital does not in any case end up in unpleasant legal situations, spent days at thematic days risus sardonicus-smiling during eight hours of political correct multidisciplinary get-togethers and invested several days at conferences entertaining managers, discussing time stealing programmes of value-based leadership, appreciating management, taking part in quality assurance campaigns, accrediting programmes and drawn up green politics in the department ... endlessly.

This editor has realized and accepted his inferior ability to learn, remember and invest time in practising the many controlling rules regarding precautions in publishing. His mediocre intelligence is only sufficient for using his professional skills as a scientifically trained psychiatrist; his intensive experiences as an editor for two scientific journals arise from his common sense obtained as a member of 200-year Humboldt tradition for education and scholarly and decent behaviour. He is, therefore, not haunting groups of academics submitting papers about effect of outreach psychoses teams, impact of shared decision making, etc for having forgotten to declare themselves, and he is not chasing the authors to the anonymized register studies about admission frequencies to make them document that they are not acting unethically, and he is not spending his, his office's or the authors' time checking the contribution of each of them to the study and to the quality of manuscripts submitted.

Instead, he remembers to ask the authors of a pharmamanuscript to elaborate a bit on a statement of "no conflict of interests", especially when he himself has heard the authors speaking as invited lecturers at various pharma-companies' satellite symposia at different congresses. And he may ask for a description of each author's contribution to a case report with 11 authors; and he politely asks for a comment when a reviewer thinks they "have read this once before in another journal", etc. In 99 out of 100 cases the editor gets a fully reasonable explanation from the authors clarifying that the problem is no problem at all. Mostly, the questions came up because the authors, just like the editor, had been occupied by the scientific question and had forgotten some of the formalities.

Scientists and researchers are creative individuals not tuned for rigid managerial regulations and control systems. If they were, they would not have been scientists and researchers, and if the demands for rigid formalistic behaviour keep increasing, we may risk that they stop their scientific activities. This would be a catastrophe because none among the legions of managers building up the control systems would be able to take over producing any kind of science. And, we must remember that the authors, before reaching the point in the process of submitting a manuscript to a journal, have been through endless control systems such as local, regional and national ethical committees, good clinical practice institutes, public and university offices concerning financial implications, e.g. in case of patents, rounds and rounds of information communication to patient organizations, colleagues, management of hospitals and departments to document that their research will put no financial burdens on the clinical departments, to say nothing of what they have been through when applying for grants. It is therefore part of an editor's job (at least the present editor) to protect the authors from unproductive managerial rigidity and the ongoing task of administrative rules.

How the editor (and the publisher) succeeds in avoiding a breach of ethical rules, infiltration of industry interests, marketing publications, other biases, plagiarism, none-referred replications, etc. is a matter of daily routine thinking, 'nose' and professional collaboration. For sure, together they should avoid an overkill of control systems for the majority because maybe one has been tempted beyond her control. To this editor, it is a question of having sufficient courage and integrity to act maturely, daring to trust your own skills and judgment and not hiding away behind lists of rules and regulations automatically presented to everyone submitting a paper to a journal.

This editor receives great support from his publishing company, which has gained experience over the years from a wealth of journals, e.g. a few years ago I received a booklet with instructions on how to handle a richness of cheat, fraud, unethical behaviour, biases and other irregularities among authors and reviewers. I gave up trying to make myself familiar with any of the situations that might arise; however, it is a relief and security to know that I, at any time, can call my publishing editor and get support from the experienced specialists if it should be necessary. Luckily, during my 16 years as an editor of two different journals it has never been necessary to take any situations that far. Most of the situations I have encountered turned out to be harmless, and the few serious situations have always been solved in scholarly and in mutual, however not loving, understanding. In cases where I doubted my own judgement in complicated matters, I have been able to seek advice from one or two of the board members with specific insight into ethical problems concerning publication, not forgetting to mention the many informal conversations had with the secretary of the journal and the publishers, solving many problems without dramatizing trivial problems.

Epidemiologia e Psichiatria Sociale, 19, 3, 2010 
How did it come so far that mistrust and maybe also paranoia occupy so much time in the publishing process? Of course we have severe cases of fraud, undeclared personal interests from reviewers, plagiarism, dependence on pharma-industry, etc. These severe cases quite often come from the battlefield where patents, billions of $£, \$, €$, prestige, awards and prizes are at stake. The problem is only seen very occasionally in a humble, middle ranking clinical oriented journal like the Acta Psychiatrica Scandinavica responsible for the ongoing (clinical) research debate and communication.

Publishing is a fruitful and pleasant process, a professional collaboration and discussion between equals: the author, the reviewer, the editor and the reader, all of them taking their positions with one journal only to meet another fine day at another journal, the editor now being the author, the reader and the author now acting as reviewers, and the reviewers being the readers. This underlines the importance of direct and decent personal communication between authors and editors and between reviewers and editors. Regrettably, this communication has over the past couple of years been severely complicated by the introduction of different communication engines, utilizing hundreds of prewritten standard letters created for any imaginable situation. It should be admitted that these systems bring some advantages to the editing office in handling manuscripts; it brings several advantages to the publishing company when receiving and processing manuscripts from editorial offices. It brings paramount advantages to the firms producing and handling the systems, not least updating them, ongoing problems to the editorial office when receiving letters about changes and updates, mostly because these letters are written in a shop lingo not respecting that editing offices are not part of the producers of the e-communication systems.

This editor does not know whether it is an advantage to the submitting authors. I myself have long ago given up submitting papers to journals; this is now handled by expert secretaries in our institute. Judged by the furious emails we occasionally receive from frustrated authors, it is a problem for other authors too. I suppose that only authors younger than 16 years of age are able to beat the engines totally without problems.
This brings up a recollection from the European Psychiatric Association Congress in Lisbon in early 2009. One of the former chairmen of the organization, Norman Sartorius, gave a workshop to the group of Young Psychiatrists about Leadership in Psychiatry during which he stated - not as a part of a discussion, but a statement: "You cannot be a leader without being present".

The major challenge concerning modern technology is to keep up a parallel personal direct communication with authors, reviewers and board members. This part of the electronic rationalization costs me an awful lot of Saturday and Sunday hours to keep the invaluable personal contact alive. However, I do this extra investment of time with pleasure because of the privilege it is to communicate with honest, dedicated, creative, bright and educated colleagues all over the world; authors, readers, reviewers publishers and board members, giving me a feeling of gratitude and humbleness to be given the honour of acting as a moderator, a facilitator in the efforts to improve the life situations for fellow human beings suffering from mental illnesses.

And what concerns the paranoia, the mistrust, the rules and regulations, and technical progress I happily remember what the now retired legendary managing director of 'my' publishing company, worshiped and adored by his editors said to me when starting as an editor of the Acta Psychiatrica Scandinavica: "your responsibility is to give the contents of the Acta Psychiatrica Scandinavica the highest possible quality. The rest: printing, layout, circulation, dissemination, management, advertisement, you name it, will be taken care of in the publishing company" (Munk-Jørgensen, 2003).

\section{REFERENCES}

Munk-Jørgensen P. (2003). The privilege of editing a scientific journal. Epidemiologia e Psichiatria Sociale 12, 1.

Munk-Jørgensen P., Christiansen B. \& Licht RW. (2009). Can't lead from behind - Happy New Year 2009. Acta Psychiatrica Scandinavica 119, 1-3.

Munk-Jørgensen P. Christiansen B. \& Licht RW. (2010). Your paper has been accepted for publication. Acta Psychiatrica Scandinavica 121, 1-3. 